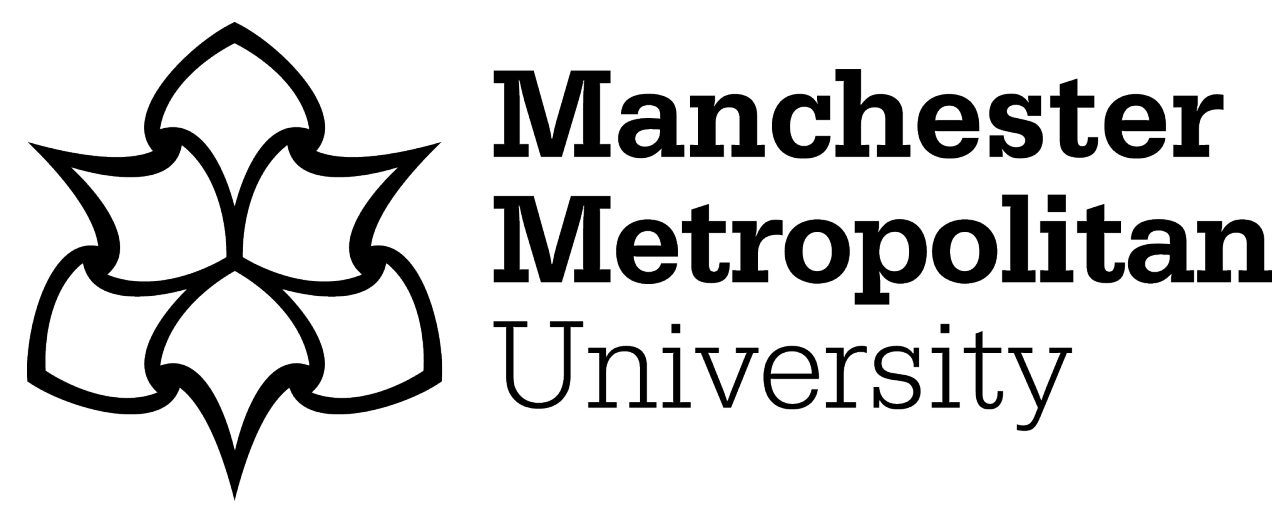

Heaslip, V and Serrant, L ORCID logoORCID: https://orcid.org/0000-00029382-9859 (2019) Research readiness: A core aspect of fitness for practice? Nurse Education Today, 79. pp. 32-34. ISSN 0260-6917

Downloaded from: https://e-space.mmu.ac.uk/623638/

Version: Accepted Version

Publisher: Elsevier

DOI: https://doi.org/10.1016/j.nedt.2019.05.005

Usage rights: Creative Commons: Attribution-Noncommercial-No Derivative Works 4.0

Please cite the published version 


\section{RESEARCH READINESS: A CORE ASPECT OF FITNESS FOR PRACTICE?}

\section{Introduction}

Florence Nightingale is one of the most famous nurses in history, credited for establishing the origins of nurse education and training. What is not so commonly known however, is her work in promoting evidence based practice and foundations of nursing research. Following her return from the Crimean war she was committed to understanding the reasons for the high mortality rates; in that for every single soldier who died from their injuries another 7 soldiers died from diseases such as dysentery, cholera (Robins 1997) and septicaemia (Joyce 2008) which led her to work with a team of experts to systematically explore the reasons for this. The published royal commission report detailed Nightingale's initial ideas, the terms of reference for the review, the data analysis and recommendations for change (McDonald 2001). Nightingale's approach is clearly linked to contemporary nurse research projects in which an area for investigation is identified; a proposal is developed, while methodically articulating the process of investigation (research), choice of methods, data analysis, and recommendations. This systematic search for evidence and knowledge remains at the heart of current nursing professional practice as clinical judgements are made regarding the provision of patient care. Indeed the International Council of Nurses (2012) assert the responsibility of each nurse to develop research based professional nursing knowledge as a core aspect of their professional role.

In order for nurses practice to be evidence based we postulate that nurse need to be 'research ready' at the point of registration. This is endorsed by nursing professional regulatory bodies who stipulate that utilising evidence to inform education, policy and practice of healthcare is an essential part of nurses' fitness to practice. In addition, in the UK as elsewhere, national strategic priorities for nurses highlight nurses' responsibility to evidence the work they do and the impact it has on patient care (NHS England 2016; Nursing Council New Zealand 2016). Thus, research is included in nursing education and training programmes and promoted by a variety of nursing regulatory bodies, national nursing strategies worldwide. However, effective clinical research requires facilitative environments to support high quality research as well as trained and knowledgeable research professionals (Loke et al 2014). As such, there are two core considerations in the preparation of undergraduate nurses in research: firstly, equipping students with skills and knowledge to understand, utilise and create evidence to underpin nursing practice. Secondly, ensuring practice environments facilitate application of the acquired skills and knowledge in the clinical setting. This raises two key questions: 
- $\quad$ how prepared are newly qualified nurses to be able to understand, utilise and create evidence for clinical practice?

- $\quad$ are clinical environments and learning support systems equipped to facilitate nurses in utilising their research skills in clinical practice?

\section{Educational preparation for research readiness}

Nurse education has the potential to positively influence student's attitudes and skills in research and evidence based practice (Henoch et al. 2014). However very few undergraduate nursing students actually undertake primary research (creating evidence) with many programmes falling short by restricting students to conducting a literature review; scoping and analysing utilising published research in order to make recommendations for practice. Reasons for this include the large numbers of nursing students and the perceived complexities of obtaining ethical approval make undertaking primary research difficult to achieve. In addition, the lack of clinical nurses' involvement in research often results in little research engagement during practice placements and students are left struggling to understand how to maintain or apply research skills on leaving the academic setting (Brook et al. 2015). Loke et al (2014) contends that research and evidence based practice must extend beyond nursing preparatory programmes, and be further developed within the health care setting in order to appreciate the complexities of evidence based practice within the clinical context.

\section{Clinical environments and research}

Whilst research and evidence based practice are firmly espoused in the nurses professional role, paradoxically there is a split between research and clinical practice in that they are often seen as opposing areas of professional development. For example, less than $1 \%$ of all nurses in America have a doctorate degree (Nickitas and Feeg 2011), and of those, the majority will not be working in clinical practice settings but rather in universities and in nurse education (Ketefian and Redman 2015). This picture of a small number of nurses holding doctorates and the majority of which working in nurse education, is not isolated to America but is reflected across the world. Therefore those with the skills to undertake independent research are often located away from clinical practice, and due to the demands of an academic nursing role have little time or capacity to maintain strong clinical links by working in clinical practice. Likewise nurses working in clinical settings have high clinical workloads which leave little time for conducting and engaging in clinical nursing research even if they felt they had the skills. There are calls to address this, for example in America the Institute of Medicine (2010) report the 'Future of Nursing' argues the need to double 
the number of nurses with a doctorate by 2020 . Whereas in the United Kingdom, there are drives to increase the numbers of clinically based nurses undertaking doctoral studies through funded fellowships, however the numbers of these are few and the competition is high. In order to be considered for one of these the individual nurse has to demonstrate research capability which in itself is challenging as, as identified earlier many of them would have had minimal engagement in clinical research. Whilst the focus on clinical research is growing, confusion often exists between clinical research nurse roles and that of nurse researchers. The career trajectory for the former remains limited with the role focusing on research nurses as agents of data collection rather than developing them as independent researchers who design and lead clinical research. In contrast, nurse researchers usually have doctorate level education which equips them with the knowledge and skills to develop and lead whole research projects (Jones 2015). Nurse researchers usually work in universities as nurse academics or jointly working across a university and a clinical practice area as a Clinical Academic (Department of Health 2012).These disparate career pathways compound the challenge of embedding research into the nursing profession and nursing practice. The result is a fracturing of academic experience and practice engagement of research, negatively impacting nurses' ability to understand, utilise and generate evidence to inform changes needed to enhance patient care.

\section{Barriers to 'research readiness'}

Numerous papers have been written exploring barriers to nurses' research readiness within these similar themes emerge: Firstly is the skill set of staff; research with 243 nurses from northern Israel by Eizenberg (2011) identified that nurses with a degree have a higher probability of using evidence based practice than nurses who do not have a degree. This could be linked to their educational preparation in that nurses with a degree are more likely to have been exposed to research within their degree studies. This raises interesting challenges especially for countries like the UK who did not move to all graduate entrance until 2013 and, furthermore many other countries that still have a significant proportion of non-graduates in their nursing workforce. The second general theme that emerges links to language specifically the complexity of language used in research reports which acts as a barrier to clinical engagement. Research in Australia by Hendricks and Cope (2017) with 95 registered nurses identified that $96 \%(n=90)$ of the respondents expressed they would read research articles more if they were presented in 'simpler' language, while a further $42 \%(n=39)$ identified that research language prevented them from applying research into their practice. This is a tension, in that for many nurses who are research active working in academic institutions, there are expectations of them with regards to research quality exercises such as the Research Excellence 
Framework (REF) which judge outputs in terms of originality, significance and rigour (REF 2019) and results in expectations for them not to publish their research in professional nursing journals but rather high impact academic journals. Research by Koya and Chowdhury (2017) identified a correlation in science based studies between publishing in high impact journals and scoring highly in the REF exercise. Publishing in high impact academic journals can perpetuate the research jargon than many clinically based nurses struggle to understand. Alongside language the context in which nurses' work also acts as a barrier. A cross-sectional study of 210 Iranian nurses by Bahadori et al (2016) identified that staff perceived time to be the largest barrier to using research within their practice; noting both a lack of time to read research or to implement new ideas into practice.

Comparing nursing to medicine, it is apparent that medicine has been more successful in embedded research into its professional practice. Research by Paget et al. (2014) identified that there are increased opportunities for doctors to become involved in research compared to nurses and other allied health professionals. Reasons for this are multi-faceted; a key aspect is the endorsement of the British Medical Association who ensures research is an integral part of their under and post graduate training and continued professional development. The 'Every doctor a scientist and a scholar' report by the British Medical Association (2015) clearly establishes the importance of linking clinical practice to the evidence base identifying the key skills required. In doing this, it clearly sets out the expectation that Doctors are to be engaged in research throughout their professional careers, a concept which is not commonplace within nursing; indeed many nurses do not perceive research to be part of their role. Therefore as a profession we need to address this as a matter of urgency, to cement research as an integral aspect of evidence based practice which promotes high quality patient care.

\section{Final thoughts}

This paper explores the critical relationship between research readiness and fitness to practice in an international nursing context. The authors here therefore assert, that far from being disparate requirements nurse educators have a responsibility to ensure that research and practice are unified and that nurses at the point of qualification and beyond are research ready and research able respectively. Nursing preparatory programmes need to build sense of agency and empowerment in student nurses so they have confidence to drive the research and evidence based practice agenda in clinical practice. This is more than developing in them a sense of scholarship; we also need to identify ways of converging nurses as researchers, educationalist and clinical practitioners rather than requiring the individual to select disparate distinct career pathways. In summary, we argue that 
failure to ensure that education programmes and clinical practice environments equip nurses with the knowledge, skills and opportunities to understand, create and utilise research evidence (figure 1) fails to adequately prepare them for practice in the 21 st century

\section{References}

Bahadori, M., Raadabadi, M., Ravangard, R., Mahaki, B., 2016. The barriers to the application of the research findings from the nurses' perspective: A case study in a teaching hospital. Journal of Education and Health Promotion, 5, 14

Brooke, J., Hvalič-Touzery, S., Skela-Savič, B., 2015. Student nurse perceptions on evidence-based practice and research: An exploratory research study involving students from the University of Greenwich, England and the Faculty of Health Care Jesenice, Slovenia. Nurse Education Today 35 (2015) e6-e11 http://dx.doi.org/10.1016/i.nedt.2015.02.026

Department of Health., 2012. A Strategy for Developing Clinical Academic Researchers within Nursing, Midwifery and the Allied Health Professions. Leeds: Department of Health

Eizenberg, M., 2011. Implementation of evidence-based nursing practice: nurses' personal and professional factors? Journal of Advanced Nursing 67(1), 33-42

Hendricks, J., Cope, V., 2017. Research is not a 'scary' word: Registered nurses and the barriers to research utilisation. Nordic Journal of Nursing Research, Vol. 37(1), 44-50

Henoch, I., Jakobsson Ung, E., Ozanne, A., Falk, H., Falk, K., Kenne Sarenmalm, E., Öhlén, J., Fridh, I., 2014. Nursing students' experience of involvement in clinical research: An exploratory study. Nurse Education in Practice 14, 188-194

Institute of Medicine, 2010. The Future of Nursing. Washington; Institute of Medicine

International Council of Nurses., 2012. The ICN Code of Ethics for Nurses. Switzerland; International Council of Nurses

Jones, H., 2015. Clinical research nurse or nurse researcher? Nursing Times, 111(19), 12-14

Joyce, H., 2008. Florence Nightingale: a lady with more than a lamp. Significance, Dec, 181-2 Available from: $\quad$ https://rss.onlinelibrary.wiley.com/doi/pdf/10.1111/j.17409713.2008.00327.x [accessed 1.3.2019]

Ketefian, S., and Redman, R., 2015. A critical examination of developments in nursing doctoral education in the United States. Revista Latino- Americana De Enfermagem, 23(3), 363-371

Koya, K., and Chowdhury, G., 2017. Metric-based vs peer-reviewed evaluation of a research output: Lesson learnt from UK's national research assessment exercise. PLOS ONE https://journals.plos.org/plosone/article?id=10.1371/journal.pone. 0190337 
Loke, J., Laurenson, M., Wai Lee, K., 2014. Embracing a culture in conducting research which requires more than nurses' enthusiasm. Nurse Education Today 34 132-137

McDonald, L., 2001. Florence Nightingale and the early origins of evidence based nursing. Evidence Based Nursing 4, p 68-9

NHS England, 2016. Leading Change; adding value a framework for nursing midwives and care staff. London: NHS

Nickitas, D., Feeg, V., 2011. Doubling the number of nurses with a doctorate by 2020: predicting the right number or getting it right? Nursing Economics 29(3), p109

Nursing Council for New Zealand, 2016. Competencies for registered nurses. Nursing Council for New Zealand: Wellington

Paget, SP., Lilischkis, KJ., Morrow, AM., Caldwell, PHY., 2014. Embedding research in clinical practice: differences in attitudes to research participation among clinicians in a tertiary teaching hospital. Internal Medicine Journal. Available from: https://onlinelibrary.wiley.com/doi/pdf/10.1111/imj.12330 [accessed 1.3.2019]

Research Excellence Framework., 2019. Guidance on Submission, available from: https://www.ref.ac.uk/publications/guidance-on-submissions-201901/ [accessed 1.3.2019]

Robins, C., 1997. Cholera and Dysentry in the Crimean War: a layman's view. Journal of the Society for Army Historical Research 75(304); 240-245 